\title{
Changes in the anaclitic-introjective personality configurations following psychoanalytic psychotherapy with young adults
}

\author{
Andrzej Werbart, Siri Aldén, Anders Diedrichs \\ Department of Psychology, Stockholm University, Sweden
}

\begin{abstract}
\end{abstract}
Treatment goals in psychoanalytic psychotherapy often include changes in underlying psychological structures, rather than only symptom reduction. This study examines changes in the anaclitic-introjective personality configurations following psychoanalytic psychotherapy with young adults in relation to outcomes. Thirty-three patients were interviewed pretreatment and at termination using the Object Relations Inventory (ORI). Prototype Matching of Anaclitic-Introjective Personality Configuration (PMAI) was applied to the ORI material by two independent judges (intraclass correlation coefficient $=0.73$ ). The patients were classified pretreatment as predominately anaclitic $(n=13)$ or introjective $(n=20)$. Outcome measures included the Symptom Checklist-90-R (SCL-90) and Differentiation-Relatedness scale (D-R) pretreatment, at termination, at the 1.5-year and three-year follow-up. Both groups improved post-treatment in terms of symptoms and developmental levels of representations of self, mother, and father. No significant differences between the anaclitic and the introjective group were found in this respect, and could not be expected due to the low power $(0.27)$. The anaclitic group showed better balance between relatedness and self-definition post-treatment, while this improvement was not significant in the introjective group. Further and larger studies are needed to draw more farreaching conclusions about the relations between changes in personality configurations over the course of treatment and the treatment efficacy. The clinical implications of this approach to underlying dynamic psychological structures are discussed.

Key words: Personality; Relatedness; Self-definition; Outcomes; Psychoanalytic psychotherapy.

\section{Introduction}

Treatment goals in psychoanalytic psychotherapy often include changes in underlying psychological structures, rather than only symptom reduction or more adaptive behavioral patterns. As early as 1957, David Rapaport defined structures in psychological functioning as enduring configurations of behaving, thinking and feeling that undergo slow processes of change. Accordingly, the psychoanalytic notion of structural change has usually been described in terms of increased differentiation and integration of relatively stable mental organization. It is also well-known that symptom-based, descriptive diagnoses, such as DSM-IV (APA, 2000) can create difficulties for clinicians with regards to equifinality and multifinality, i.e., different etiological factors can lead to the same symptom, and the same symptom can be included in different diagnoses (Luyten \& Blatt, 2011, 2013). As repeatedly demonstrated by Sidney Blatt (2004) and colleagues (Blatt \& Zuroff, 1992; Luyten, Blatt, \& Fonagy, 2013), 
different personality-related difficulties might lead to similar symptoms of depression, but require different treatments, tailored to the patient's personality features. This study aims to examine changes in personality configurations following psychoanalytic psychotherapy with young adults in relation to outcomes.

According to Blatt's double helix model, psychological development is a lifelong negotiation between two fundamental dimensions in human experiences: relatedness and self-definition (Blatt, 2008; Blatt \& Luyten, 2009; Luyten $\&$ Blatt, 2011, 2013). From infancy to old age, a synergic interaction continues between these two fundamental polarities. Development of the sense of self (the introjective line) leads to increasingly mature levels of interpersonal relatedness (the anaclitic line) that, in turn, facilitate further differentiation and integration in the development of the self. Growth in both lines of development is eventually integrated into a mature self-identity: a self in relation with others. Psychological well-being involves meaningful selfidentity as well as meaningful attachments, that is, a balance between differentiation and relatedness; individuation and intimacy. However, most individuals, also within the normal range of psychological development, have an inclination towards either the relatedness dimension or the self-definition dimension. In contrast, different forms of psychopathology reflect an exaggerated and distorted preoccupation with one or the other of these developmental dimensions (Luyten \& Blatt, 2011, 2013).

When Erikson (1968) formulated his ideas on the psychosocial development of ego identity, he described adolescence as a time of identity crisis and inner turmoil, whereas the crisis in young adulthood was one of intimacy versus isolation. Implicit in these early formulations is the dialectical interplay between two interwoven developmental lines: the development of identity is connected to self-definition, while the capacity for intimacy is a matter of relatedness. Hence, adolescence and young adulthood are together a crucial time for a synthesis that can result in a consolidated identity and a capacity for mature relating. However, it is also a time when failures to integrate these two fundamental developmental processes might result in psychological distress and psychopathology (Blatt \& Blass, 1996; Blatt \& Luyten, 2009; Luyten \& Blatt, 2013). The last few decades have seen a disturbing increase in the prevalence of mental disorders among young adults in Western societies, where young people are given an extended period in which to explore their future possibilities (Arnett, 2000). This period of emerging adulthood lays the foundation for future parental roles and, consequently, for the next generation (see, Adatto, 1991). Accordingly, a study of changes in the anaclitic-introjective personality configurations in young people seeking professional help for their difficulties might enrich our knowledge about this period of ongoing strain, about possibilities for integrating a more stable self-identity, and about mechanisms of change in psychotherapy.
Although Blatt (1974) initially formulated this difference between relational and self-definitional dimensions of personality as a distinction between anaclitic (or dependent) and introjective (or self-critical) forms of depression, he increasingly came to use this earlier terminology to refer to psychopathology, and the terms relatedness and self-definition to refer to psychological development and functioning in general (see Blatt, 1995a; Blatt \& Blass, 1996). The anaclitic configuration is connected with difficulties in close relationships and attachment anxiety, while the introjective configuration is connected with excessive demands for achievement and perfectionism, and attachment avoidance (Luyten \& Blatt, 2013). Thus, anaclitic depression centers on feelings of loneliness, abandonment, and neglect, and introjective depression focuses on issues of self-worth and feelings of failure and guilt (Blatt, 1974, 2004; Blatt \& Luyten, 2009).

It should be noted that disturbances in each developmental line might lead to similar symptoms, but require different treatments, and they respond differently to the same therapeutic interventions. For example, excessive striving for recognition might lead to isolation and loneliness, a state similar to that of an abandoned, relationseeking person. The introjective person needs help to reconsider his/her striving towards independence, whereas the anaclitic person is in need of safety and support. Early studies (such as the Austen Riggs study and re-analysis of data from the Menninger Psychotherapy Research Project and from the Treatment of Depression Collaborative Research Program) pointed at the necessity of different therapeutic interventions for patients with different personality configurations. Introjective patients were more responsive to interpretive-exploratory interventions and changed primarily in the area of clinical symptoms, whereas anaclitic patients were more responsive to supportive interventions and showed improved quality in their interpersonal relationships (Blatt, 1995b; Blatt \& Auerbach, 2003; Blatt, Besser, \& Ford, 2007; Blatt \& Ford, 1994; Blatt, Ford, Berman, Cook, \& Meyer, 1988; Blatt, Sanislow, Zuroff, \& Pilkonis, 1996; Blatt \& Shahar, 2004; Blatt, Zuroff, Bondi, Sanislow, \& Pilkonis, 1998; Blatt, Zuroff, Hawley, \& Auerbach, 2010; Luyten \& Blatt, 2013).

Accordingly, Luyten and Blatt (2011) proposed a model of psychopathological disorders conceptualized as prototypical constellations of interpersonal relatedness and self-definition at different developmental levels of organization, ranging from normal personality functioning to full-blown symptom and/or personality disorders. These dimensions were incorporated in the proposed revision of the Diagnostic and Statistical Manual of Mental Disorders (DSM) (Skodol, 2012) and eventually included in the Alternative DSM-5 Model for Personality Disorders (APA, 2013), whose Criterion A consists of an impairment in self (identity and self-direction) and interpersonal (empathy and intimacy) functioning. This dimensional model 
was demonstrated to be considered by clinicians as more useful than the former categorical DSM classification (Morey, Skodol, \& Oldham, 2014).

The question remains of how the anaclitic-introjective personality configuration changes following psychotherapy and which methods are best suitable for studying such changes in underlying dynamic structures. In order to approach this issue, we developed an instrument for assessment of anaclitic-introjective personality dimensions, based on matching interview data or clinical material with prototype descriptions of these two personality configurations (Werbart \& Forsström, 2014; Werbart \& Levander, 2016). The prototype-matching method is close to clinical reasoning and resembles the natural tendency of human thinking for typification and classification (Westen, Shedler, \& Bradley, 2006; Westen, DeFife, Bradley, \& Hilsenroth, 2010). Furthermore, independent assessment, rather than self-reports, such as the Depressive Experiences Questionnaire (DEQ; Blatt, D'Afflitti, \& Quinlan, 1976), has the advantage of allowing judgment of aspects of personality not directly accessible to the person's own experience and not confounded by the patient's treatment experiences.

In a previous study of 14 cases of publicly financed psychoanalysis, the method of prototype-matching was applied to an investigation of changes in anaclitic-introjective personality dimensions in relation to self-rated outcomes. Most patients showed clinically significant improvements at termination and at two-year follow-up. For the anaclitic cases symptom reduction was accompanied by more mature integration of anaclitic and introjective personality dimensions, while the introjective cases could show symptom reduction without such improvement (Werbart \& Forsström, 2014). In a subsequent qualitative study we found that both groups of patients experienced their changes in terms of having developed a more mature personality and at least some integration of the opposite polarity. Asked post-termination to describe their analysis, the anaclitic patients focused on both positive and negative aspects of the analytic relationship, whereas introjective patients commented on both positive and negative aspects of the analyst as a person (Werbart $\&$ Levander, 2016).

The objective of the present study was to examine changes in the anaclitic-introjective personality configuration following psychoanalytic psychotherapy with young adults in relation to outcomes in terms of self-rated symptoms and the developmental level of representations of self and significant others. How do the initially anaclitic and the initially introjective group differ with regards to the balance between relatedness and self-definition at termination? Do the two patient groups show different outcome patterns at termination and longterm follow-ups? Are changes in the anaclitic-introjective balance related to changes on other outcome measures? Following previous studies, we expected a development towards better balance between relatedness and self-definition in both groups. Furthermore, we expected more pronounced improvement in the developmental level of representations of self and others in the anaclitic group and a greater symptomatic improvement in the introjective group.

\section{Materials and Methods}

\section{Setting}

The present study is based on archival data from the Young Adult Psychotherapy Project (YAPP), a longitudinal, prospective, naturalistic study of psychoanalytic individual and group psychotherapy at the former Institute of Psychotherapy in Stockholm, Sweden. The project was approved by the Regional Research Ethics Committee at the Karolinska Institutet and all participants gave their informed consent. A total of 134 patients were included ( $73 \%$ female; mean age $=22$; range $=18-25 ; \mathrm{SD}=2.2)$ of whom 92 were offered individual psychotherapy and 42 group therapy. The main complaints, presented in pretreatment interviews, were low self-esteem (97\%), depressed mood (66\%), anxiety (55\%), and conflicts in close relationships (66\%) (Wiman \& Werbart, 2002).

The psychotherapies were conducted in accordance with standard descriptions and procedures of psychoanalytic psychotherapy without use of an explicit treatment manual. The treatments generally aimed at helping the young adults to overcome developmental arrest and to better handle strains in everyday life. The goals, duration and frequency of therapy were adjusted to individual patient needs and formalized in a written, renegotiable contract between therapist and patient. All included treatments ended by mutual agreement. The treatments were conducted by 37 therapists who all shared a psychoanalytical frame of reference, even though working quite autonomously with varying preferences regarding theory and technique. The patients offered individual psychotherapy stayed in treatment for a mean of 22.2 months $(\mathrm{SD}=17.2 ; \mathrm{Mdn}=20$; range $=0-85$; with the nine nonstarters excluded, $\mathrm{M}=24.6 ; \mathrm{SD}=16.3 ; \mathrm{Mdn}=21$; range $=2-$ 85 ) with a frequency of one or two sessions per week. All nine outcome measures except the developmental level of the representation of mother changed significantly during treatment and showed significant positive change from pretreatment to the 1.5-year follow-up (Lindgren, Werbart, \& Philips, 2010).

\section{Participants}

To be included in the present study, the patients had to be in the age span 18-25 at the start of psychoanalytic psychotherapy; furthermore, patient interviews and outcome data pretreatment and at termination had to be available. Owing to the research design, the patients were interviewed pre-treatment in only every second case. 
Thus, of the 92 patients in individual therapy, 33 could be included (Figure 1). Of these, all data at the 1.5 year follow-up were available in 30 cases, and at the three-yearfollow-up in 26 to 30 cases, depending on the instrument.

Twenty-seven of the patients were women and six were men. The average age at the start of psychotherapy was 22.3 years $(\mathrm{SD}=2.1$; range $18-25)$. Fourteen patients lived alone, ten lived with a partner, seven lived with their parents, while two lived with a friend. None were married or had a child. The most common occupation was fulltime study (20 patients) followed by full-time work (eight patients) and work in combination with studies (four patients); one patient was on sick leave. Thirty-one patients were born in Sweden; five had at least one parent of foreign origin. In all, 24 patients had at least one parent with a university degree, thus indicating a high socioeconomic status within their family of origin.

Psychiatric diagnoses in accordance with DSM-IV-TR (APA, 2000) axis I were made retrospectively by two independent experts based on interview transcripts, casebook notes, and other available research and clinical data. The agreement between the experts was tested based on the assessment of 20 cases, and was found to be satisfactory (Cohen's kappa $\kappa=0.71$ ). Consensus diagnoses were used in further analyses. Personality disorders were diagnosed by the patients' therapists by completing checklists covering all the general and specific criteria of axis II personality disorders. This procedure was in accordance with claims that valid assessments of personality disorder must either be based on longitudinal data collected by skilled

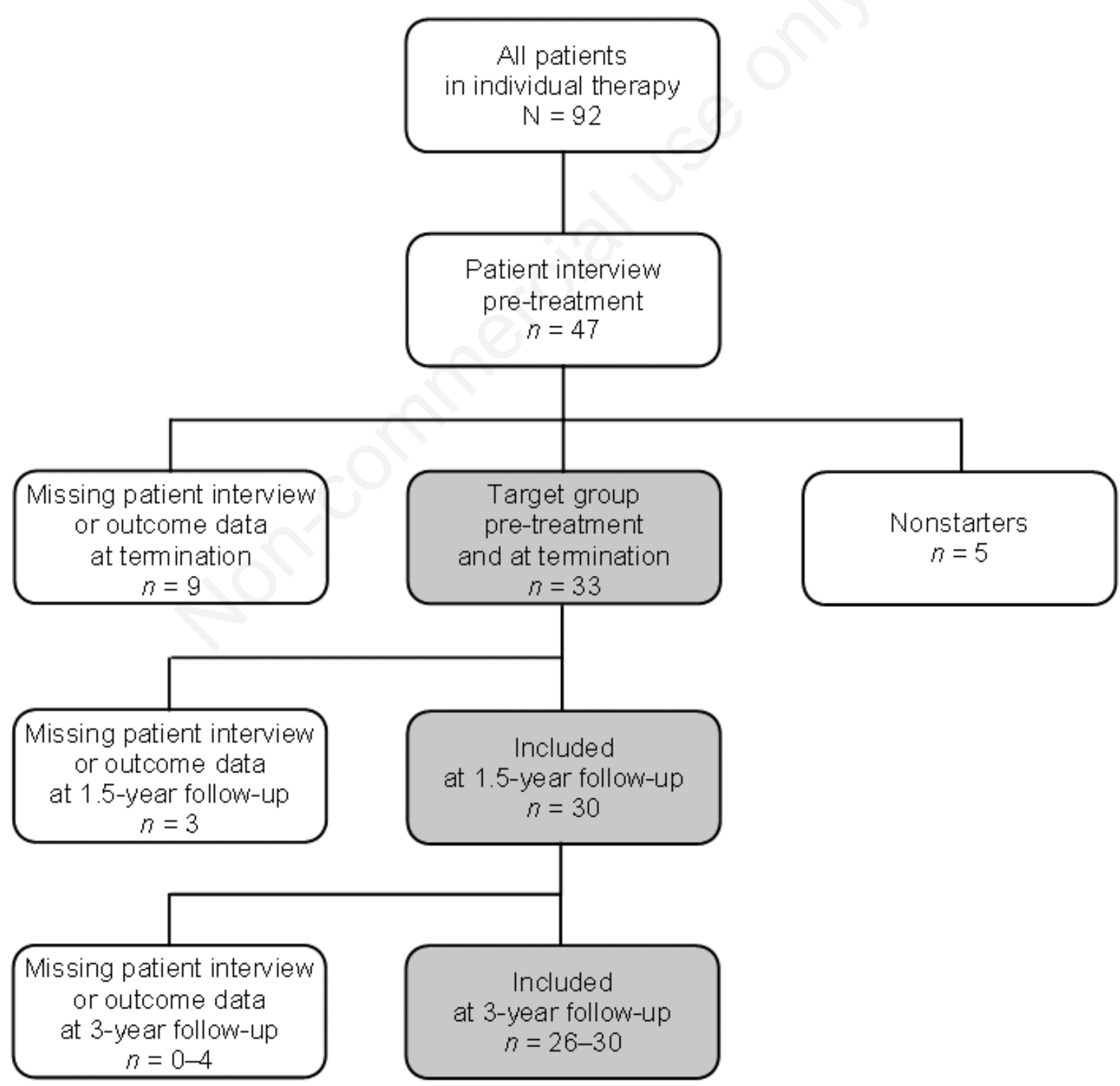

Figure 1. Attrition flow-chart from admission to target group pre-treatment and at follow-ups. 
clinicians or thorough interviews investigating the person's interpersonal history and behavior during the interview (Westen, 1997). Twenty-three patients had one or more axis I-diagnoses: six had anxiety disorder, ten had depression, two had obsessive-compulsive disorder, two had alcohol or substance abuse, and one had acute stress disorder. Twelve patients fulfilled criteria for one or more personality disorders (PD): in cluster A, two had paranoid $\mathrm{PD}$; in cluster $\mathrm{B}$, two had borderline PD and two had antisocial PD; in cluster $C$, three had avoidant PD. Furthermore, three patients had personality disorder not otherwise specified, three had the research diagnosis of depressive PD, and one had passive-aggressive PD; four patients had no psychiatric diagnosis. Fifteen patients had previous outpatient or inpatient psychiatric contact; 13 had previous psychotherapeutic contact.

\section{Treatments}

The 33 included patients were treated by 22 therapists; 15 female and seven male; 11 were social workers, nine were psychologists and two were psychiatrists. Their mean age at the start of treatments was 56 years (range 36-64; $\mathrm{Mdn}=58, \mathrm{SD}=6.7$ ). All but one of the therapists were licensed psychotherapists with two to 15 years' experience after being licensed $(\mathrm{Mdn}=13, \mathrm{M}=10.7, \mathrm{SD}=4.1)$, seven of them being psychoanalysts, and each working as a teacher and supervisor in an advanced psychotherapy training program. One therapist had basic psychotherapy training. Two therapists had three patients, nine had two patients, and 11 had one patient each. Two of the patients were treated by two different therapists. The mean time in therapy was 23.7 months (range $7-55 ; \mathrm{SD}=12.6$ ).

\section{Interviews}

The patients were interviewed prior to psychotherapy, at termination, 1.5 years and three years later using the Object Relations Inventory (ORI; Diamond, Kaslow, Coonerty, \& Blatt, 1990; Gruen, \& Blatt, 1990; for review see Huprich, Auerbach, Porcerelli \& Bupp, 2016). The material for this study consists of their answers to the ORI questions, Please give a description of yourself, your mother, father, and posttreatment also your therapist. The spontaneous response was followed by an inquiry. The interviewer inquiringly repeated adjectives or descriptive words used by the participant, e.g., You said naive? Detached, what do you mean? The audio-recorded interviews were transcribed verbatim and used for ratings of Differentiation-Relatedness of Self and Object Representations and of Prototype Matching of Anaclitic-Introjective Configuration (see below).

\section{Outcome measures}

A self-report questionnaire, Symptom Checklist-90-R (SCL-90; Derogatis, 1994), was used to assess psychiatric symptoms experienced over the previous seven days. The
90 items were rated on five-point Likert-scales ranging from 0 (not at all) to 4 (very much). The SCL-90 has demonstrated adequate reliability (Derogatis, Rickels, \& Rock, 1976) and for the Swedish translation a Cronbach's alpha of .97 has been reported (Fridell, Cesarec, Johansson, \& Malling Thorsen, 2002). As the nine subscales are highly correlated, the global symptom index (GSI) was used for the analyses in this study.

Developmental levels of representations of self, mother, and father were assessed applying the ten-point Differentiation-Relatedness scale (D-R; Blatt \& Auerbach, 2001, 2003; Blatt, Auerbach, \& Behrends, 2008; Diamond, Blatt, Stayner, \& Kaslow, 1991). D-R assumes that, with psychological development, representations (i.e., cognitive-affective schemas or internal working models) of self and others become increasingly differentiated and integrated and begin to express an increased appreciation of mutual relatedness. Generally, the D-R level six or seven is regarded as the cut-off between the clinical and nonclinical range (Levy, Blatt, \& Shaver, 1998). A reliability study based on part of the YAPP material reported good interrater agreement ( $\mathrm{ICC}=0.71$; Hjälmdahl, Claesson, Werbart, \& Levander, 2001). Consensus ratings, previously performed by a group of trained clinicians, were used in the present study.

\section{Assessment of personality configurations}

The patients were categorized as predominantly anaclitic or introjective pretreatment and at termination, following the procedure of Prototype Matching of Anaclitic-Introjective Personality Configuration (PMAI; Werbart \& Levander, 2016). The judges assessed the extent to which the ORI data matched prototype descriptions of both anaclitic and introjective personality (Appendix), using a scale ranging from 1 (little or no match) to 5 (very good match). A previous study demonstrated satisfactory interrater agreement ( $\mathrm{ICC}=0.65$; Werbart \& Forsström, 2014). The present study combines binary classification and dimensional PMAI ratings.

Two judges (the second and third authors) were trained in PMAI ratings, using 20 ORI interviews not included in the present study (due to missing data on some time point). Subsequently, the judges performed independent ratings of half of the material (33 interviews), achieving intraclass correlation of 0.730 . Cases of disagreement (a difference of two or more scale points) were discussed with the first author in order to reach a better understanding of the procedure and consensus. As a next step, the two judges rated the remaining material (a further 33 interviews), achieving ICC of 0.707. Again, cases of disagreement were subject to consensus discussion. For the total body of material, the ICC was 0.726 . In subsequent statistical analyses, we used the mean value of the two raters if the between-rater difference did not exceed one scale point, and consensus ratings in cases of greater disagreement. For categorical classification, Cohen's 
kappa was 0.56 in the first step and 0.81 in the second step ( 0.60 for the total body of material).

\section{Data analysis}

\section{Changes in the anaclitic-introjective personality configurations}

After treatment, a score reduction on the predominant PMAI dimension, together with increased score on the opposite dimension, was regarded as an indicator of a more mature integration of relatedness and self-definition. Changes on both dimensions were merged in a new variable by adding change on the predominant dimension to inverted change on the opposite. A series of paired t-tests for dependent samples (two-tailed) were used for pre-post treatment and between-group comparisons.

\section{Outcome patterns}

Based on GSI, the initially anaclitic and the introjective group were compared in terms of proportion of improved and non-improved patients. Patients were classified as belonging to the clinical range or functional distribution pre- and posttreatment, and at posttreatment as improved (reliable change and crossing the cut-off between clinical and nonclinical population, or reliable change only) or as non-improved (no reliable change or reliable deterioration). For movement into a functional distribution, the cut-off between the clinical and nonclinical range was determined in accordance with the Jacobson and Truax (1991) criterion (c), as recommended when the distributions of the functional and dysfunctional population overlap. Comparing the pretreatment YAPP sample to Swedish norms, the GSI cut-off was calculated as 0.90 .

On the group level, pre-post treatment changes on GSI and D-R in the anaclitic and the introjective patients were studied in terms of effect sizes (Cohen's $d$ and Hedges' $g$ corrected for small samples). For between-group differences in outcomes we used standardized residual gain scores and one-way ANOVA.

\section{Changes in the anaclitic-introjective balance in relation to other outcomes}

The Pearson product-moment correlation coefficient was calculated for the merged change on PMAI and residual gain scores on GSI and D-R (mean level for representations of self, mother, and father) at termination.

\section{Power analysis}

This study was limited to 33 participants (13 assessed as anaclitic and 20 as introjective). For the two-tailed ttest for independent samples with 0.05 alpha level and 0.5 effect size, the statistical power was $27 \%$. This implies an imminent risk of type II error (false negative).

\section{Results \\ Changes in the anaclitic-introjective personality configurations}

The categorical assessments of prototype matching resulted in 13 patients being classified as predominately anaclitic and the remaining 20 patients as predominately introjective pretreatment. At termination, the classification changed from anaclitic to predominately introjective in five cases, and from introjective to predominately anaclitic in another four cases, resulting in 12 patients being classified as anaclitic and 21 as introjective.

The dimensional PMAI ratings showed, for both groups, mean score reduction on the predominant personality dimension and increased mean score on the opposite dimension from pretreatment to termination (Table 1 and Figure 2). Adding change on the predominant dimension to inverted change on the opposite dimension, the change towards a better balance of relatedness and self-definition was significant for the total patient group $[t(65)=3.25$, $\mathrm{P}=0.002]$. Further analysis showed a significant reduction on the predominant dimension $[t(32)=3.04, \mathrm{P}=0.005]$, while the change on the opposite dimension was not significant

Table 1. Dimensional Prototype Matching of Anaclitic-Introjective Personality Configuration ratings in both groups pre-treatment and at termination.

\begin{tabular}{lcccc}
\hline PMAI & \multicolumn{2}{c}{ Anaclitic group $\mathbf{( n = 1 3 )}$} & \multicolumn{2}{c}{ Introjective group (n=20) } \\
\hline Pre-treatment & $\mathrm{M}$ & $\mathrm{SD}$ & $\mathrm{M}$ & $\mathrm{SD}$ \\
Anaclitic dimension & 3.07 & 0.49 & 1.65 & 0.49 \\
Introjective dimension & 1.88 & 0.36 & 3.15 & 0.69 \\
\hline Termination & & & & \\
Anaclitic dimension & 2.42 & 0.70 & 1.85 & 0.81 \\
Introjective dimension & 2.23 & 0.75 & 2.88 & 0.51 \\
\hline
\end{tabular}

PMAI, Prototype Matching of Anaclitic-Introjective Personality Configuration; M, mean; SD, standard deviation. 
$[t(32)=1.64, \mathrm{P}=0.11]$. Looking at each group separately, the change towards a better balance was significant for the initially anaclitic patients $[t(12)=2.55, \mathrm{P}=0.025]$, but not for the initially introjective group $[t(19)=1.61, \mathrm{P}=0.125]$.

\section{Outcome patterns}

In terms of clinical symptoms (GSI), most patients $(85 \%)$ belonged to the clinical range pretreatment. Looking at the total patient group at termination, $57 \%$ showed reliable improvements (both patients with clinically significant symptom reduction and patients with reliable change only), and the proportion of improved patients increased at the follow-ups (Table 2). At termination, these improvements were more frequent in the initially introjective group, while at the follow-ups the proportion of improved patients was larger in the initially anaclitic group.
Descriptive statistics of outcome data and effect sizes on group level are presented in Table 3. In terms of symptom reduction, both groups improved with medium to large effect sizes at termination and the follow-ups. The developmental level of representations of self and parents improved with large effect sizes in the anaclitic group (but medium Hedges' $g$ for D-R Father at termination), while the variation in effect sizes was larger in the introjective group, with small effect sizes for D-R Mother at termination and medium effect size for D-R Father at 1.5-year follow-up.

Mean values for outcome measures in both groups pre- and post-treatment are presented in Figure 3. Pretreatment, the between-group differences in symptom severity and levels of Differentiation-Relatedness were not significant. A one-way ANOVA (based on standardized residual

\section{Anaclitic group}

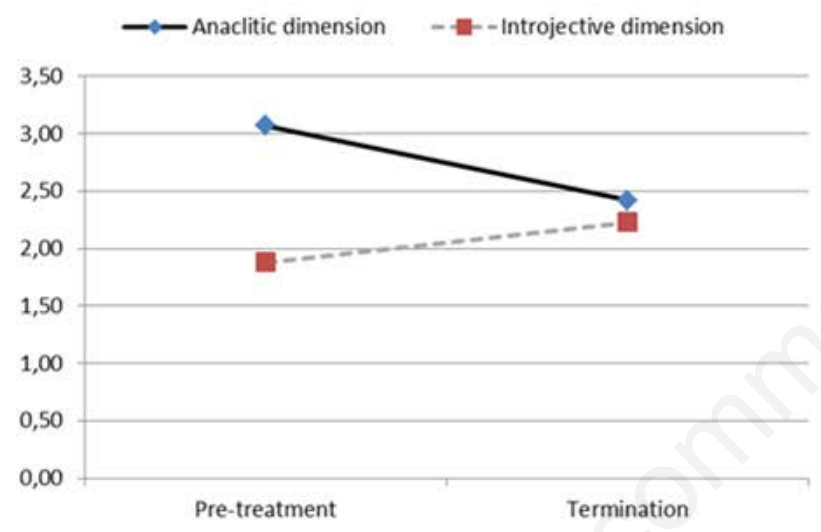

Introjective group

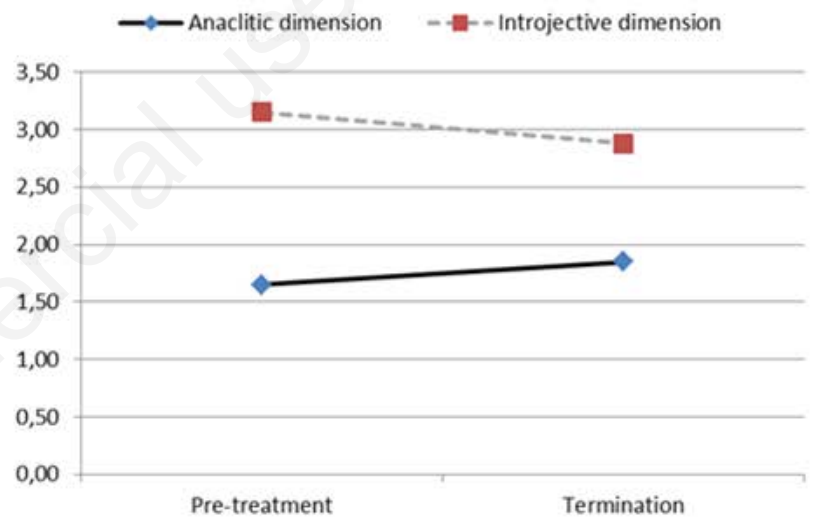

Figure 2. Pre-post change in prototype matching of anaclitic-introjective personality configuration ratings of the anaclitic and the introjective dimension in both groups.

Table 2. Patients below and above clinical cut-off, improved patients (clinically significant improvement or reliable change only) and non-improved patients (no reliable change or deterioration).

\begin{tabular}{|c|c|c|c|c|c|c|c|c|c|c|c|c|}
\hline \multirow[t]{2}{*}{ GSI } & \multicolumn{3}{|c|}{ Pre-treatment } & \multicolumn{3}{|c|}{ Termination } & \multicolumn{3}{|c|}{ 1.5-year follow-up } & \multicolumn{3}{|c|}{ 3-year follow-up } \\
\hline & $\underset{n=13}{A}$ & $\underset{n=20}{I}$ & $\begin{array}{l}\text { Total } \\
\mathbf{n}=\mathbf{3 3}\end{array}$ & $\underset{n=12}{A}$ & $\underset{n=18}{I}$ & $\begin{array}{l}\text { Total } \\
\mathbf{n}=\mathbf{3 0}\end{array}$ & $\underset{n=12}{A}$ & $\underset{n=18}{I}$ & $\begin{array}{l}\text { Total } \\
\mathbf{n}=\mathbf{3 0}\end{array}$ & $\underset{n=11}{A}$ & $\underset{n=15}{I}$ & $\begin{array}{l}\text { Total } \\
n=26\end{array}$ \\
\hline Clinical range & $\begin{array}{c}12 \\
(92)\end{array}$ & $\begin{array}{c}16 \\
(80)\end{array}$ & $\begin{array}{c}28 \\
(85)\end{array}$ & $\begin{array}{c}4 \\
(33)\end{array}$ & $\begin{array}{c}4 \\
(22)\end{array}$ & $\begin{array}{c}8 \\
(27)\end{array}$ & $\begin{array}{c}4 \\
(33)\end{array}$ & $\begin{array}{c}5 \\
(28)\end{array}$ & $\begin{array}{c}9 \\
(30)\end{array}$ & $\begin{array}{c}6 \\
(55)\end{array}$ & $\begin{array}{c}5 \\
(33)\end{array}$ & $\begin{array}{c}11 \\
(42)\end{array}$ \\
\hline Functional Distribution & $\begin{array}{c}1 \\
(8)\end{array}$ & $\begin{array}{c}4 \\
(20)\end{array}$ & $\begin{array}{c}5 \\
(15)\end{array}$ & $\begin{array}{c}8 \\
(67)\end{array}$ & $\begin{array}{c}14 \\
(78)\end{array}$ & $\begin{array}{c}22 \\
(73)\end{array}$ & $\begin{array}{c}8 \\
(67)\end{array}$ & $\begin{array}{c}13 \\
(72)\end{array}$ & $\begin{array}{c}21 \\
(70)\end{array}$ & $\begin{array}{c}5 \\
(45)\end{array}$ & $\begin{array}{c}10 \\
(67)\end{array}$ & $\begin{array}{c}15 \\
(58)\end{array}$ \\
\hline Improved & - & - & - & $\begin{array}{c}6 \\
(50)\end{array}$ & $\begin{array}{c}11 \\
(61)\end{array}$ & $\begin{array}{c}17 \\
(57)\end{array}$ & $\begin{array}{c}9 \\
(75)\end{array}$ & $\begin{array}{c}12 \\
(67)\end{array}$ & $\begin{array}{c}21 \\
(70)\end{array}$ & $\begin{array}{c}7 \\
(64)\end{array}$ & $\begin{array}{c}9 \\
(60)\end{array}$ & $\begin{array}{c}16 \\
(62)\end{array}$ \\
\hline Non-improved & - & - & - & $\begin{array}{c}6 \\
(50)\end{array}$ & $\begin{array}{c}7 \\
(39)\end{array}$ & $\begin{array}{c}13 \\
(43)\end{array}$ & $\begin{array}{c}3 \\
(25)\end{array}$ & $\begin{array}{c}6 \\
(33)\end{array}$ & $\begin{array}{c}9 \\
(30)\end{array}$ & $\begin{array}{c}4 \\
(36)\end{array}$ & $\begin{array}{c}6 \\
(40)\end{array}$ & $\begin{array}{c}10 \\
(38)\end{array}$ \\
\hline Missing & - & - & - & 1 & 2 & 3 & 1 & 2 & 3 & 2 & 5 & 7 \\
\hline
\end{tabular}

GSI, global symptom index; A, anaclitic group; I, introjective group; N varies due to the varying number of respondents at each assessment. Cut-off between clinical and nonclinical population for GSI $=0.90$. Values in brackets are expressed as percentage. 
Table 3. Descriptive statistics and effect sizes of outcome data for the anaclitic and the introjective group pre-treatment at 1.5year and 3-year follow-up.

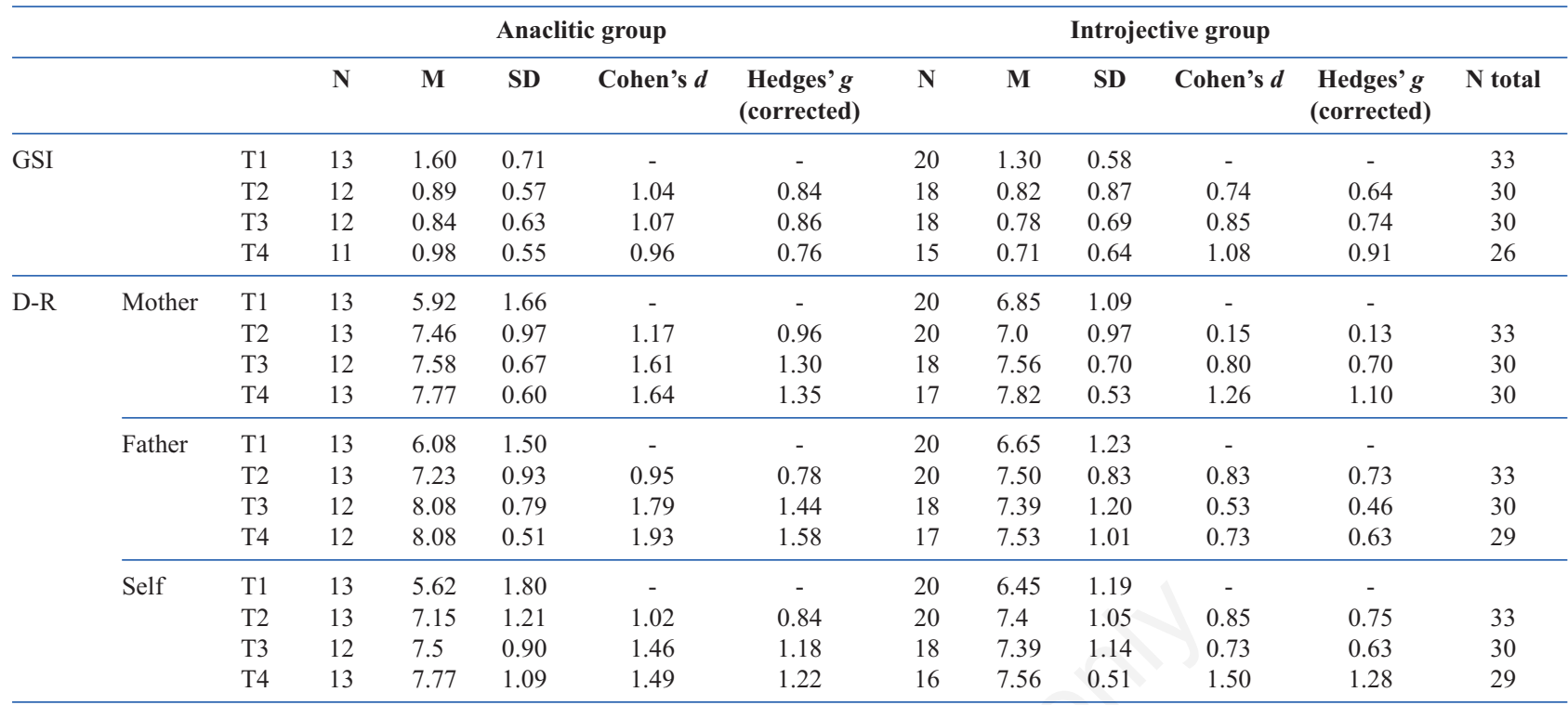

M, mean; SD, standard deviation; GSI, global symptom index; T1, pre-treatment; T2, termination; T3, 1.5-year follow-up; T4, 3-year follow-up. N varies due to the varying number of respondents at each assessment.

GSI

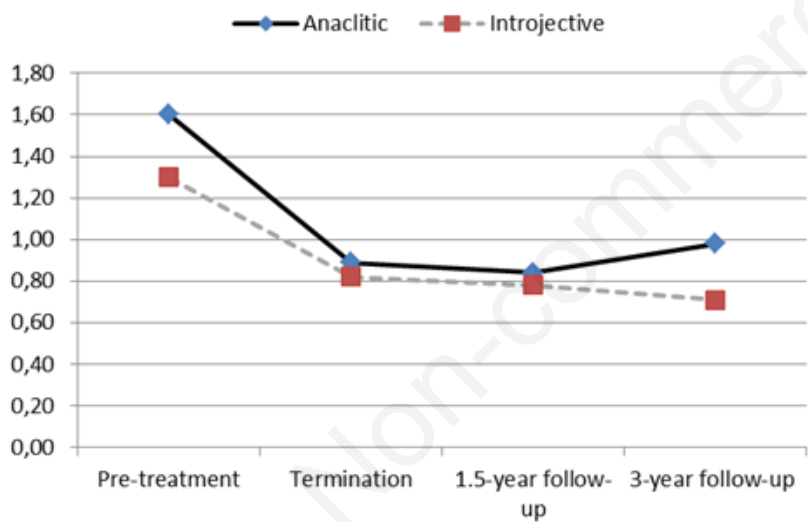

\section{D-R Father}

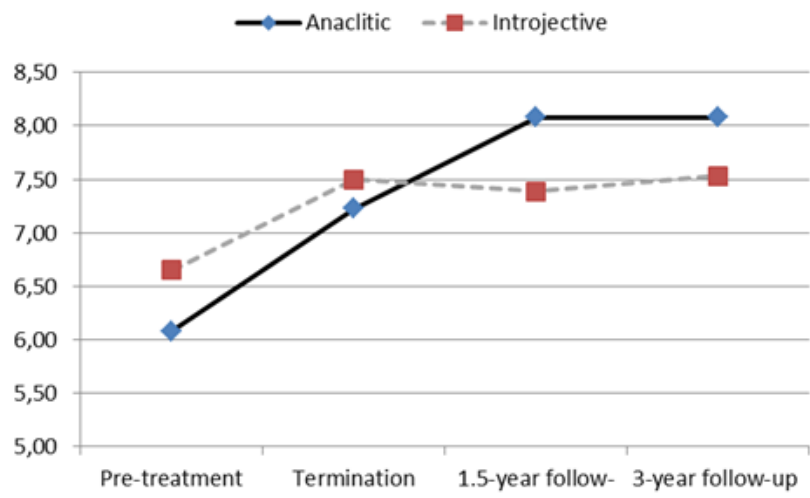

up
D-R Mother

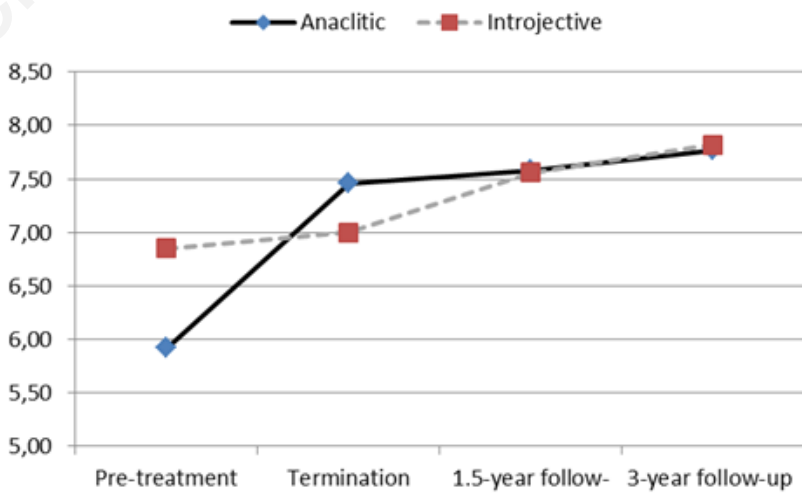

up

\section{D-R Self}

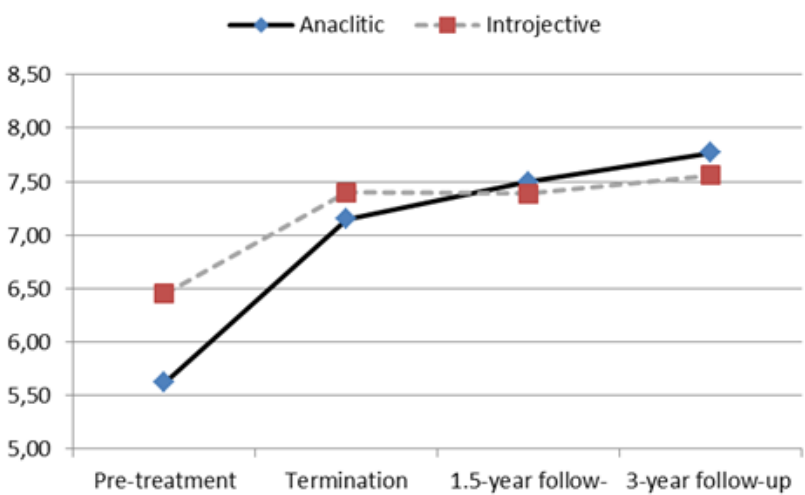

up

Figure 3. Mean values for outcome measures in both groups pre-treatment, at termination, 1.5-year follow-up, and 3-year follow-up. 
gain scores) revealed no significant differences in outcomes between the anaclitic and the introjective group, except a tendency for smaller improvement in D-R Father at the 1.5-year follow-up in the introjective group $[F(1$, $\left.30)=3.31, \mathrm{P}=0.08, \eta^{2}=0.11\right]$.

\section{Changes in the anaclitic-introjective balance in relation to other outcomes}

For the total patient group, there was a significant positive correlation between the merged change on PMAI (sum of change on the predominant dimension and inverted change on the opposite dimension) and residual gain scores on GSI at termination ( $r=0.38, \mathrm{P}=0.039)$. Thus, the change towards increased balance between relatedness and self-definition was associated with lower levels of symptom reduction. No significant correlation was found between the merged change on PMAI and the mean change on D-R.

\section{Discussion}

Previous research has been able to demonstrate differences in treatment outcomes between patients with predominantly anaclitic and introjective personality features, but only a few studies have examined changes in the balance between these two personality dimensions. The present study indicates positive changes following psychoanalytic psychotherapy in a sample of young adults. These changes are: better integration of anaclitic and introjective personality dimensions, reduction of selfrated symptoms, and higher expert-rated developmental levels of representations of self and parents. However, changes in the anaclitic-introjective personality configurations were statistically significant in the anaclitic, but not in the introjective group. Generally, the gains on outcome measures were maintained over a three-year followup period. No significant differences between the anaclitic and the introjective group were found in outcome measures, and could not be expected due to the low power. These results must be interpreted with caution given the study's methodological limitations. Nevertheless, the observed between-group difference is in line with a previous study of patients in psychoanalysis, indicating that twice as many anaclitic patients, as compared to introjective patients, met the criterion of improved anaclitic-introjective balance post-treatment (Werbart \& Forsström, 2014).

In terms of reliable change in clinical symptoms, most of the patients improved at termination and follow-up. Looking at the proportion of patients in the functional distribution (below the cut-off between clinical and nonclinical population), the distribution was comparable to meta-analytic data: $15 \%$ at pretreatment, $73 \%$ at termination and $70 \%$ at 1.5 year follow-up (Table 2), as compared to the mean distribution reported by de Maat et al. (2013): 29\% at pretreatment, $77 \%$ at termination and $75 \%$ at follow-up.

In the anaclitic group, effect sizes at all measurement points (Table 3; Hedges' $g$ ) were large or close to large both for symptom reduction (between 0.76 and 0.86 ) and for developmental levels of representations of self and parents (between 0.78 and 1.58). In the introjective group, effect sizes for symptom reduction varied between medium (0.64) and large (0.91), and for developmental levels of representations of self and parents between small (0.13) and large (1.28). However, the between-group differences on outcome measures were not significant. This might have been because of a type II error, or due to lack of actual differences in group means, as suggested by Figure 3. According to previous studies, the anaclitic patients tend to improve the quality of their interpersonal relationships, whereas the therapeutic changes in the introjective group are most evident in the area of clinical symptoms (Blatt \& Auerbach, 2003; Blatt, Besser, \& Ford, 2007; Blatt \& Ford, 1994; Blatt, Ford, Berman, Cook, \& Meyer, 1988; Luyten \& Blatt, 2013). The results of the present study seem to suggest more pronounced improvement in the developmental level of representations of self and parents in the anaclitic group, but no marked tendency for greater symptomatic improvement in the introjective group.

Furthermore, we found no significant correlation between changes in the anaclitic-introjective balance and changes in the mean developmental levels of representations of self and parents. Surprisingly, changes in the anaclitic-introjective balance were correlated with an increase in clinical symptoms. Thus, this correlation was in the opposite direction to what was expected. This result is difficult to interpret and the possibility to draw any conclusions is severely limited by the low $\mathrm{N}$ in each group and by the relatively simple method of analysis. A closer examination revealed that most of the participants improved both in terms of improved balance and of symptom reduction. However, in some cases better balance was accompanied by deterioration in clinical symptoms, and in some others, symptom reduction was accompanied by impaired balance. Furthermore, a large change on the merged balance variable (sum of change on the predominant dimension and inverted change on the opposite dimension) might cover contradictory developments with high levels on the initially non-predominant dimension and shift in personality orientation from anaclitic to introjective or the opposite (as in nine cases in this study). Taken together, the counterintuitive correlation and contradictory developments found in the present study might mirror an ongoing interplay between developmental processes and new strains in life in young adults. In a study of hospitalization-based psychodynamic treatment of personality disorders, based on 111 cases and another methodology for assessment of change in personality configuration (DEQ), changes in dependency and in self-critical perfectionism were associated with symptomatic improvement (Lowyck, Luyten, Vermote, Verhaest, \& Vansteelandt, 2016). However, the issue of improved balance was not addressed there. 
Blatt's theoretical model of normal development, psychopathology and therapeutic process (Blatt, 2008; Blatt \& Luyten, 2009; Luyten \& Blatt, 2013) has the advantage of pinpointing factors pertinent to how the therapeutic relationship is established and used to promote development and change, and what kind of difficulties might appear with a particular patient. Being aware of the patient's personality configuration, the therapist might form an idea of the patient's capability to establish an attachment to the therapist and the patient's potential reactions to therapeutic boundaries, separations, as well as different kinds of interventions. For example, anaclitic patients might easily establish a therapeutic bond but be sensitive to experienced incompatibilities in the therapeutic relationship, or experience the therapeutic frames and the therapist's neutral stance as a hindrance. Introjective patients, for their part, might appreciate the therapist's professional attitude but experience difficulties in being together with the therapist, and may be excessively preoccupied by issues concerning how they perform as psychotherapy patients (cf., Levander \& Werbart, 2012; Werbart \& Levander, 2016). Furthermore, what seems to be the patient's defense might be an expression of a patient's characteristic personality configuration, and patients with different personality configurations might use distinct defenses in the therapeutic process (cf., Cramer \& Blatt, 1993). Likewise, the Rogerian Conditions of empathy, positive regard and genuineness, provided by the therapists, might have different meaning for anaclitic patients with maladaptive dependency and introjective patients with self-critical perfectionism (Zuroff, Shahar, Blatt, Kelly, \& Leybman, 2016). In order to adjust the psychotherapeutic technique to the anaclitic and introjective patients' different needs and defenses, the therapist has to monitor moment-to-moment changes, as well as longitudinal trends in the patient's dynamic balance between relatedness and self-definition. This might also be an incentive to interventions fostering a more mature balance by focusing on the polarity opposite to the patient's characteristic personality style.

Furthermore, the two-polarities model enables therapists to reflect on the dynamics in the therapeutic relationship, starting from the interplay between the patient's and the therapist's predominant personality configuration. Therapists might expect to feel and react differently depending on whether their characteristic focus on relatedness or self-definition is concordant or complementary to the patient's personality configuration. In this respect, the dynamics in the therapeutic relationship are co-created and influenced by both the patient's and the therapist's personality orientations.

\section{Strengths and limitations}

Despite an extensive body of empirical research, based on Blatt's double helix model, there is still a scarcity of studies addressing changes in the anaclitic-introjective personality configurations following treatment (however, see a study of 14 cases in psychoanalysis, based on the assumption that this treatment modality is especially suitable for promoting such changes; Werbart \& Forsström, 2014; Werbart \& Levander, 2016). The present study is the first one exploring changes in the anaclitic-introjective personality configurations among young adult outpatients, i.e., people in a period of life when the dialectics of relatedness and self-definition might be especially vivid. This time, the PMAI judges achieved a better interrater agreement $(\mathrm{ICC}=0.73)$ than in the previous investigation (ICC $=0.65$ ). This is probably due to a more extensive and elaborated training, as also reflected in the increase of Cohen's kappa from 0.56 in the first step to 0.81 in the second step of categorical assessment. Furthermore, this study demonstrates that the relatively limited ORI material can be used for reliable assessment of the anacliticintrojective personality configurations.

However, the findings rest on a small patient sample, not representative of young adult outpatients in other forms of long-term treatment. The low statistical power of this study limited the possibility of finding potential significant differences in outcome between the anaclitic and the introjective group. Consequently, the observed between-group differences in proportion of improved patients and in effect sized are hard to interpret.

Another limitation is associated with the discrepancy between the high abstraction level of the two-polarities model and the specificity and concreteness of PMAI ratings. With only two personality categories it might be difficult to capture a sufficient amount of specific variance when comparing outcomes for these two groups (cf., Luyten \& Blatt, 2016). Furthermore, the forced dichotomous categorization of personality features in the present study did not take into consideration potential mixed anaclitic-introjective psychopathology (cf., Shahar, Blatt, \& Ford, 2003). Likewise, PMAI ratings lack the dimension of the degree of integration of focus on relatedness and focus on self-definition (however, this is represented in this study by $\mathrm{D}-\mathrm{R}$ ratings). In clinical contexts, it is highly relevant to differentiate between anaclitic and introjective psychopathology on lower levels of maturity in personality development, and anaclitic and introjective personality features on higher levels of integration.

Several limitations of naturalistic studies are also applicable here, such as lack of a control group, limited specification of treatments, and no control of treatment integrity. Thus, it was impossible to establish a causal connection between the treatments and the observed trend towards better integration of relatedness and self-definition post-treatment. Lacking a window on the therapeutic process (such as recordings of therapy sessions), we could not observe what in the therapeutic work promoted or hindered such developments.

\section{Future direction}

An important topic for future studies is how the effectiveness of various therapeutic interventions differs be- 
tween the anaclitic and the introjective patients, and whether the two groups respond differently to the same kind of interventions. Inclusion of other measures, related to issues of relatedness and self-definition and on a lower level of abstraction (such as attachment, dysfunctional attitudes, perfectionism, etc.), might enrich the research field and contribute to validation of the PMAI. A large proportion of studies based on the two-polarities model uses reanalysis of archival data. Thus, further and larger studies, especially designed for evaluation of different aspects of Blatt's personality theory, are needed to draw more far-reaching conclusions about the relations between changes in personality configurations over the course of treatment and the treatment efficacy. Such investigations might deepen our understanding of the anaclitic-introjective personality configurations in a clinical context.

\section{Conclusions}

The present study is one of the hitherto few attempts to examine changes in the balance between relatedness and self-definition following long-term psychotherapy. Of the 33 included young adult patients, 20 were assessed pretreatment as predominately introjective (exaggerated emphasis on issues regarding self-definition), and the remaining 13 as predominately anaclitic (exaggerated emphasis on issues regarding relatedness). At termination, a majority of patients maintained their main personality configuration, whereas nine patients changed their orientation to the opposite, according to a categorical classification. Dimensional assessments showed reduced emphasis on the predominant dimension and increased emphasis on the opposite dimension in both groups at termination. However, change towards a better balance was significant only for the initially anaclitic patients. Both groups improved posttreatment in terms of symptoms and developmental levels of representations of self, mother, and father, and these gains were generally maintained up to three years after termination. No significant differences between the anaclitic and the introjective group were found in this respect. However, there were signs of more pronounced improvement in the developmental level of representations of self and parents in the anaclitic group. Contrary to previous studies, there was no marked tendency for greater symptomatic improvement in the introjective group. These results must be interpreted with caution given the study's low statistical power and other methodological limitations. The research field still needs to develop and compare different methods for measuring the balance/imbalance between relatedness and self-definition. In clinical settings, monitoring the patient's dynamic balance between relatedness and self-definition might enable the therapist to adjust the psychotherapeutic technique to the anaclitic and introjective patients' different needs and defenses. Furthermore, the two-polarities model might enable the therapists to reflect on the interpersonal dynamics during psychotherapy.

\section{References}

Adatto, C.P. (1991). Late adolescence to early adulthood. In S. Greenspan, G. Pollock (Eds.), The Course of Life (Vol. 4, Adolescence, pp. 357-375). Madison, CT: International Universities Press.

APA (2000). Diagnostic and statistical manual of mental disorders (4th ed., text rev.). Washington, DC: American Psychiatric Association.

APA (2013). Diagnostic and statistical manual of mental disorders (5th ed.). Washington, DC: American Psychiatric Association.

Arnett, J.J. (2000). Emerging adulthood: a theory of development from the late teens through the twenties. American Psychologist, 55, 469-480. doi:10.1037/0003-066X.55.5.469

Blatt, S.J. (1974). Levels of object representation in anaclitic and introjective depression. Psychoanalytic Study of the Child, 29, 107-157.

Blatt, S.J. (1995a). Representational structures in psychopathology. In D. Cicchetti \& S. Toth (Eds.), Rochester symposium on developmental psychopathology, Vol. 6. Emotion, cognition, and representation (pp. 1-33). Rochester, NY: University of Rochester Press.

Blatt, S.J. (1995b). The destructiveness of perfectionism: Implications for the treatment of depression. American Psychologist, 50, 1003-1020. doi:10.1037/0003-066X.50.12.1003

Blatt, S.J. (2004). Experiences of depression: theoretical, clinical and research perspectives. Washington, DC: American Psychological Association.

Blatt, S.J. (2008). Polarities of experience: relatedness and selfdefinition in personality development, psychopathology, and the therapeutic process. Washington, DC: American Psychological Association.

Blatt, S.J., \& Auerbach, J.S. (2001). Mental representation, severe psychopathology, and the therapeutic process. Journal of the American Psychoanalytic Association, 49, 113-159 (2001).

Blatt, S.J., \& Auerbach, J.S. (2003). Psychodynamic measures of therapeutic change. Psychoanalytic Inquiry, 23, 268-307. doi:10.1080/07351692309349034

Blatt, S.J., Auerbach, J.S., \& Behrends, R. (2008). Changes in the representation of self and significant others in the treatment process: links between representation, internalization, and mentalization. In E.J. Jurist, A. Slade, \& S. Bergner (Eds.), Mind to mind: infant research, neuroscience, and psychoanalysis (pp. 225-263). New York, NY: Other Press.

Blatt, S.J., Besser, A., \& Ford, R.Q. (2007). Two primary configurations of psychopathology and change in thought disorder in long-term intensive inpatient treatment of seriously disturbed young adults. American Journal of Psychiatry, 164(10), 1561-1567. doi:appi.ajp.2007.05111853

Blatt, S.J., \& Blass, R. (1996). Relatedness and self definition: A dialectic model of personality development. In G. G. Noam \& K. W. Fischer (Eds.), Development and vulnerabilities in close relationships (pp. 309-338). Hillsdale, NJ: Erlbaum.

Blatt, S.J., D'Afflitti, J.P., \& Quinlan, D.M. (1976). Experiences of depression in normal young adults. Journal of Abnormal Psychology, 85, 383-389. doi:10.1037/0021-843X.85.4.383

Blatt, S.J., \& Ford, R. (1994). Therapeutic change: An object relations perspective. New York, NY: Plenum.

Blatt, S.J., Ford, R.Q., Berman, W., Cook, B., \& Meyer, R. (1988). 
The assessment of change during the intensive treatment of borderline and schizophrenic young adults. Psychoanalytic Psychology, 5, 127-158. doi:10.1037/0736-9735.5.2.127

Blatt, S.J., \& Luyten, P. (2009). A structural-developmental psychodynamic approach to psychopathology: two polarities of experience across the life span. Development and Psychopathology, 21, 793-814. doi:10.1017/S0954579409 000431

Blatt, S.J., Sanislow, C.A. Zuroff, D.C., \& Pilkonis, P.A. (1996). Characteristics of effective therapists: Further analyses of data from the National Institute of Mental Health Treatment of Depression Collaborative Research Program. Journal of Consulting and Clinical Psychology, 64, 1276-1284.

Blatt, S.J., \& Shahar, G. (2004). Stability of patient-by-treatment interaction in the Menninger Psychotherapy Research Project. Bulletin of the Menninger Clinic, 68, 23-38. doi: 10.1521/bumc.68.1.23.27733

Blatt, S.J., \& Zuroff, D.C. (1992). Interpersonal relatedness and self-definition: two prototypes for depression. Clinical Psychology Review, 12, 527-562. doi.10.1016/0272-7358(92) 90070-O

Blatt, S.J., Zuroff, D.C., Bondi, C.M., Sanislow, C., \& Pilkonis, P.A. (1998). When and how perfectionism impedes the brief treatment of depression: Further analyses of the National Institute of Mental Health Treatment of Depression Collaborative Research Program. Journal of Consulting and Clinical Psychology, 66, 423-428. doi:10.1037/0022-006X.66.2.423

Blatt, S.J., Zuroff, D.C., Hawley, L.L., \& Auerbach, J.S. (2010). Predictors of sustained therapeutic change. Psychotherapy Research, 20, 37-54. doi:10.1080/10503300903121080

Cramer, P., \& Blatt, S.J. (1993). Change in defense mechanisms following intensive treatment, as related to personality organization and gender. In U. Hentschel, G.J.W. Smith, \& J.G. Draguns (Eds.), The concept of defense mechanisms in contemporary psychology (pp. 310-320). New York, NY: Springer Verlag.

de Maat, S., de Jonghe, F., de Kraker, R., Leichsenring, F., Abbass, A., Luyten, P.,..., Dekker J. (2013). The current state of the empirical evidence for psychoanalysis: A meta-analytic approach. Harvard Review of Psychiatry, 21, 107-137. doi:10.1097/HRP.0b013e318294f5fd

Derogatis, L.R. (1994). Symptom-checklist-90-R: administration, scoring and procedures manual (3rd ed., revised). Minneapolis: National Computer Systems.

Derogatis, L.R., Rickels, K., \& Rock, A F. (1976). The SCL-90 and the MMPI: a step in the validation of a new self-report scale. British Journal of Psychiatry, 128, 280-289. doi:10.1192/bjp.128.3.280

Diamond, D., Kaslow, N., Coonerty, S., \& Blatt, S.J. (1990). Changes in separation-individuation and intersubjectivity in long-term treatment. Psychoanalytic Psychology, 7, 363397. doi:10.1037/h0079215

Erikson, E.H. (1968). Identity: Youth and Crisis. New York, NY: Norton.

Fridell, M., Cesarec, Z., Johansson, M., \& Malling Thorsen, S. (2002). Svensk normering, standardisering och validering av symtomskalan SCL-90 [Swedish norms, standardisation, and validation of the symptom scale SCL-90]. Västervik, Sweden: National Board of Institutional Care (SiS).

Gruen, R.J., \& Blatt, S.J. (1990). Change in self and object representation during long-term dynamically oriented treatment. Psychoanalytic Psychology, 7, 399-422. doi: 10.1037/ h0079216
Hjälmdahl, Y., Claesson, M., Werbart, A., \& Levander, S. (2001). Bedömning av differentiering-relaterande i självoch objektrepresentationer I: En validitetsstudie. [Differentiation-Relatedness of self and object representations I: Validity of the Swedish version] (Psykoterapi: Forskning och utveckling [Psychotherapy: Research and Development], Report 20). Institute of Psychotherapy and Psychotherapy Section at Karolinska Institutet, Stockholm, Sweden.

Huprich, S.K., Auerbach, J.S., Porcerelli, J.H., \& Bupp, L.L. (2016). Sidney Blatt's Object Relations Inventory: contributions and future directions. Journal of Personality Assessment, 98, 30-43. doi:10.1080/00223891.2015.1099539

Jacobson, N.S., \& Truax, P. (1991). Clinical significance: a statistical approach to defining meaningful change in psychotherapy research. Journal of Consulting and Clinical Psychology, 59, 12-19. doi:10.1037/0022-006X.59.1.12

Levander, S., \& Werbart, A. (2012). Personality related responses to the psychoanalytic process: a systematic multicase study. Psychoanalytic Psychology, 29, 1-16. doi: 10.1037/a0024713

Levy, K.N., Blatt, S.J., \& Shaver, P.R. (1998). Attachment styles and parental representations. Journal of Personality and Social Psychology, 74, 407-419. doi:10.1037/0022-3514. 74.2.407

Lindgren, A., Werbart, A., \& Philips, B. (2010). Long-term outcome and post-treatment effects of psychoanalytic psychotherapy with young adults. Psychology and Psychotherapy: Theory Research and Practice, 83, 27-43. doi:10.1348/147608309X464422

Lowyck, B., Luyten, P., Vermote, R., Verhaest, Y., \& Vansteelandt, K. (2016). Self-critical perfectionism, dependency, and symptomatic distress in patients with personality disorder during hospitalization-based psychodynamic treatment: a parallel process growth modeling approach. Personality Disorders: Theory, Research, and Treatment. Advance online publication. doi:10.1037/per0000189

Luyten, P., \& Blatt, S.J. (2011). Integrating theory-driven and empirically-derived models of personality development and psychopathology: a proposal for DSM-V. Clinical Psychology Review, 31, 52-68. doi:10.1016/j.cpr.2010.09.003

Luyten, P., \& Blatt, S.J. (2013). Interpersonal relatedness and self-definition in normal and disrupted personality development: retrospect and prospect. American Psychologist, 68, 172-183. doi:10.1037/a0032243

Luyten, P., \& Blatt, S.J. (2016). A hierarchical multiple-level approach to the assessment of interpersonal relatedness and self-definition: implications for research, clinical practice, and DSM planning. Journal of Personality Assessment, 98, 5-13. doi:10.1080/00223891.2015.1091773

Luyten, P., Blatt, S.J., \& Fonagy, P. (2013). Impairments in self structures in depression and suicide in psychodynamic and cognitive behavioral approaches: implications for clinical practice and research. International Journal of Cognitive Therapy, 6, 265-279. doi:10.1521/ijct.2013.6.3.265

Morey, L.C., Skodol, A.E., \& Oldham, J.M. (2014). Clinician judgments of clinical utility: a comparison of DSM-IV-TR personality disorders and the alternative model for DSM-5 personality disorders. Journal of Abnormal Psychology, 123(2), 398-405. doi:10.1037/a0036481

Rapaport, D. (1957). Cognitive structures. In M. M. Gill (Ed.) (1967), The collected papers of David Rapaport (pp. 631664). New York: Basic Books.

Skodol, A.E. (2012). Personality disorders in DSM-5. Annual 
Review of Clinical Psychology, 8, 317-344. doi:10.1146/annurev-clinpsy-032511-143131

Shahar, G., Blatt, S.J., \& Ford, R.Q. (2003). Mixed anaclitic-introjective psychopathology among treatment-resistant inpatients undergoing psychoanalytic psychotherapy. Psychoanalytic Psychology, 20, 84-102. doi:10.1037/07369735.20.1.84

Werbart, A., \& Forsström, D. (2014). Changes in anaclitic-introjective personality dimensions, outcomes and psychoanalytic technique: a multi-case study. Psychoanalytic Psychotherapy, 28, 397-410. doi:10.1080/02668734.2014. 964295

Werbart, A., \& Levander, S. (2016). Fostering change in personality configurations: anaclitic and introjective patients in psychoanalysis. Psychoanalytic Psychology, 33, 217-242. doi:10.1037/pap0000022

Westen, D. (1997). Divergences between clinical and research methods for assessing personality disorders: implications for research and the evolution of Axis II. American Journal of Psychiatry, 154, 895-903. doi:10.1176/ajp.154.7.895

Westen, D., DeFife, J.A., Bradley, B., \& Hilsenroth, M.J.
(2010). Prototype personality diagnosis in clinical practice: A viable alternative for DSM-V and ICD-11. Professional Psychology: Research and Practice, 41, 482-487. doi: 10.1037/a0021555

Westen, D., Shedler, J., \& Bradley, R. (2006). A prototype approach to personality diagnosis. American Journal of Psychiatry, 163, 846-856. doi:10.1176/appi.ajp.163.5.846

Wiman, M., \& Werbart, A. (2002). Unga vuxna i psykoterapi II: Hur uppfattar de själva sina problem? [Young adults in psychotherapy II: How do they perceive their problems?]. Psykoterapi: Forskning och utveckling [Psychotherapy: Research and Development], Report 23. Stockholm, Sweden: Institute of Psychotherapy and Psychotherapy Section at Karolinska Institutet.

Zuroff, D.C., Shahar, G., Blatt, S.J., Kelly, A.C., \& Leybman, M.J. (2016). Predictors and moderators of between-therapists and within-therapist differences in depressed outpatients' experiences of the Rogerian conditions. Journal of Counseling Psychology, 63, 162-172. doi:10.1037/ cou0000139 